\title{
Anxiety among Diabetic and non Diabetic Male \& Female
}

\author{
Dr. Krishna J. Vaghela ${ }^{1}$.
}

\section{ABSTRACT}

The main purpose of the present research was to study the anxiety level among diabetic and non diabetic people (both male and female). The study was conducted over a sample of 160 people (80- male: 40 diabetic and 40 on diabetic as well as 80- female: 40 diabetic and 40 non diabetic). For the purpose of the measuring anxiety level of participants the Beck anxiety inventory was used. The obtained data were analyzed and interpreted on using statistical tools such as mean, standard deviation, and $\mathrm{t}$ - test. The results reported that statistically significant difference observed among diabetic and non diabetic male participants in relation to anxiety their level. As regarding to female participants with diabetic and non diabetic also significantly differ on their scores on anxiety. In conclusion the anxiety level was significantly higher in diabetic people both: male as well as female.

Keywords: Diabetes, Diabetic People, Non Diabetic People, Anxiety Level

Diabetes is pandemic in both developed and developing countries in 2000 there were on estimated 175 million people with diabetes worldwide. Diabetes was the $6^{\text {th }}$ leading cause of death in U S in 2002 and individuals with diabetes have a twofold risk of death compared with same aged non diabetes. (Centers for Disease Control and prevention CDC 2005). Little is known about the relationship between diabetes and anxiety. Recent evidence suggests that the rate of anxiety disorders is elevated in people with type - 1diabetes. It is estimated that $14 \%$ of people with diabetes have generalized anxiety disorder. As many as $40 \%$ of people have at least some anxiety symptoms. Anxiety disorders in people with type 1 and 2 diabetes may be associated with poor blood sugar control. WHO estimates that more than 350 million individuals throughout the world will suffer from diabetes by 2030 which is twice more than the afflicted individuals in 2000 (Aikens J.E et at 2008)

"Anxiety is a needed protection mechanism anxiety turns into a disorder when a person becomes physically. Psychologically and emotionally symptomatic fearful or distraught because of it. If it does become a disorder it can be reversed." "Anxiety is more than just feeling stressed or worried. Anxious feeling is a normal reaction to a situation where a person feels under pressure

\footnotetext{
${ }^{1}$ Associate Professor \& Head, Department of Psychology, Yogiji Maharaj Mahavidyalaya, Dhari, Dist. Amreli,(Gujarat)

*Responding Author

(C) 2016 I K Vagela; licensee IJIP. This is an Open Access Research distributed under the terms of the Creative Commons Attribution License (http://creativecommons.org/licenses/by/2.0), which permits unrestricted use, distribution, and reproduction in any Medium, provided the original work is properly cited.
} 
and usually passes once the stressful situation has passed or the stressor is removed." Anxiety can be expressed in different ways such as uncontrollable worry, intense fear (phobias). Anxiety is difficult to control and is accompanied by somatic symptoms including heart palpitations, shaking, crying, and excessive perspiration. General anxiety disorder can cause physical and psychological symptoms. They often develop slowly and very in severity from person to person.

Symptoms of anxiety : Muscle tension, headache, fatigue, restlessness, irritability diarrhea, racing heart, snowballing worries, tightening of the chest, hot and cold flushes, feeling of being tense, felling a lump in your throat, stomachache or being easily distracted, difficulty concentrating, shortness of breath impatience, trouble, obsessive thinking and compulsive behavior, trouble sleeping, fatigue, trouble concentrating, nervousness.

Types of diabetes: - Diabetes mellitus is a condition in which the blood is too high because the body cannot use it properly. There are two main types of diabetes. Type -1 and type -2 . Type 1 diabetics taken daily injections to provide the insulin needed for proper cell functioning. Type - 2 not produced in sufficient quantities and or the body becomes resistant to the effects of insulin. In India nearly $75 \%$ of the type -2 diabetic have first degree family history of diabetes including a strong familial aggregation.

Some anxiety disorders have also been found to be more prevalent among diabetes patients than among non diabetics. In a review of 18 studies with a total of 4076 participants (2584 diabetic patient 1492 control participants) Grigshy abderson. Freedland, Clouse and Lustmam (2002) examined the prevalence of anxiety disorders and anxiety symptoms in type - 1 and type -2 diabetes patients. Keita, G. P. (2007) showed that the prevalence of depression and anxiety were higher among women than men, this statistics has also been observed among women with diabetes. There are some biological and socio economic factors that clarify the reason of higher depression and anxiety of female group such as hormonal changes during pregnancy, postpartum and premenopausal periods, genetic vulnerability and being dependent to others. Mark P \& Richard R (1997) levels and risk of depression and anxiety symptomatic among diabetic adults and found diabetes is associated with increased risk of psychological disturbance especially for those with more diabetes related complications. Barker L, Zhang X, Strain T, Ford E (2008) found people diagnosed with diabetes are approximately $20 \%$ more likely to suffer from anxiety than those without diabetes. Greater than $70 \%$ of diabetes cold develops microevolution conditions including heart attack, and stroke. Furthermore between 5\% and 10\% are reported to experience micro vascular complications ranging from problems with eyes limbs and kidneys. Lyrakos (2013) conducted the study to compare the level of depression, anxiety and stress in men and women diabetes mellitus patients. Analysis showed that the women were at significant risk factor for depression, anxiety and stress than male with diabetes mellitus patients. 


\section{AIMS AND OBJECTIVES:}

The purpose of the present research was to know the difference of anxiety level among diabetic and non-diabetic people (both male \& female). Some special objectives are needed to frame to study the problem. The main objectives are furnished as under.

- To find out the level of anxiety among diabetic and non-diabetic male.

- $\quad$ To find out the level of anxiety among diabetic and non-diabetic female.

\section{Hypotheses:-}

The present study has been designed to test the following null hypotheses.

- There would be no significant difference among diabetic and non-diabetic male in relation to their anxiety level.

- There would be no significant difference among diabetic and non-diabetic female in relation to their anxiety level.

\section{METHOD}

\section{Sample and procedure:-}

In the present research the researched used the simple random sampling technique for the collection of sample. Total population of the present study area was one hundred and sixty people between the age 30 to 40 years. (both :- diabetic and non-diabetic ) from Junagadh city. Out of 160 respondents 80 were male people (40 diabetic male \& 40 non-diabetic female). All the participants were matched on the variables age, gender education, marital status, are etc. The data has been collected with the help of questionnaire to measure anxiety, the beck anxiety inventory was used to for designation of presence of anxiety in participants. This test consists of 21 questions. After establishing the report with the respondents were requested to give their opinion by filling the requested information in their respective questionnaire. As well as the respondents have requested not to leave any item unanswered and incomplete. All the respondents voluntarily participants in the present research and confidentiality assured to them. After the completion of data collection all the data were coded numerically to protect the participant's privacy.

\section{Data analysis}

The researcher put the data edited and coded together in a carefully designed table for statistical analysis t-test was applied to see the significance of the difference between diabetic and non diabetic participants (both male and female). On the basis of their anxiety scores.

\section{RESULTS \& DISCUSSION}

The purpose of the present research was to know the difference of anxiety level among diabetic and non-diabetic people (both male \& female). The following interpretation was made on the basis of the analyzed data. The present research findings were based on the responses of 160 diabetic and non-diabetic participants. First hypothesis put forward that hypothesis 'there would 
be no significant difference among diabetic and non-diabetic male in relation to their anxiety level'. To assess this hypothesis t-test was used. Table- 1 gives the descriptive statistics for each two groups on their anxiety level (as defined by the diabetic male non-diabetes male). From Table-1 t-test revealed statistically significant difference between the mean number of two groups, were group-1 (diabetes male) has $\mathrm{M}=35.09$ and group-2 (non-diabetes male ) has $\mathrm{M}=28.10$ as the t-value (3.44) is found to be significant at 0.01 level of significance. Hence the null hypothesis is rejected and it clearly indicates that group-1 (diabetic male) found a significantly higher anxiety level compared with non-diabetes male (group-2).

Table-1 showing results of t-value of anxiety of diabetes and non-diabetes male.

\begin{tabular}{|l|c|c|c|c|c|}
\hline $\begin{array}{l}\text { Male } \\
\text { participates }\end{array}$ & No. & Mean & S.D. & t-value & Sig. \\
\cline { 1 - 3 } & 40 & 35.09 & 8.23 & \multirow{2}{*}{3.44} & 0.01 \\
\hline Non Diabetic & 40 & 28.10 & 9.89 & & \\
\hline
\end{tabular}

Table-2 showing results of t-value of anxiety of diabetes and non-diabetes female.

\begin{tabular}{|l|c|c|c|c|c|}
\hline $\begin{array}{l}\text { Female } \\
\text { participates }\end{array}$ & No. & Mean & S.D. & t-value & Sig. \\
\hline Diabetic & 40 & 34.29 & 8.84 & 3.1 & 0.01 \\
\hline Non Diabetic & 40 & 27.66 & 10.03 & & \\
\hline
\end{tabular}

Second hypothesis put for word that hypothesis that, 'there would be no significant difference among diabetic and non-diabetic female in relation to their anxiety level'. Results from table-2 the mean score of anxiety in the diabetes female $(M=34.29)$ and non-diabetes female $(M=27.66)$ and the t-value is (3.1) found to be significant at the 0.01 level of significance. Therefore the null hypothesis is also rejected and it is found that as regarding the anxiety level there is statistically significant difference between two comparative groups of diabetic and non-diabetic female. Female diabetic people have higher anxiety score compared with female non-diabetic people. As regarding the anxiety symptoms are more common in both male as well as female with diabetes. As well as anxiety is one of the most frequent disease among all other psychiatric disorders.

\section{CONCLUSIONS}

The purpose of the present research was to examine the difference on anxiety among diabetic and non diabetic people (both: male and female). After analysis and interpretation the following conclusions were drawn. In the present research paper through light on the significant difference between diabetic and non diabetic male on their anxiety level. With regard to anxiety scores of comparative groups of female diabetic and non diabetic participates also found statistical 
significant differ on their level of anxiety. People with diabetes are more likely to suffer anxiety than non diabetic people.

\section{Acknowledgement:}

The author of the present research gratefully acknowledges the cooperation of all the individuals who voluntarily participated in the present research. Without them the research would not have been possible. As well as under thanks responsible entities this kindly helped in the present research.

\section{REFERENCES}

Aikens, J. E. Perknis, A. Piette, D. Lipton, B. \& Erkins, W. D. (2008) Association between depression and Type -2 diabetic outcomes varies by diabetes regimen, Department of Family Medicine, Uni. Of Michigan and Center for Outcomes Research, Boston, Journal Compilation Diabetes UK, 25. 1324-1329.

Collins M, Corcoran, P (2008) Psychology anxiety and depression symptoms in patients with diabetes, Sonora, Uni. of California cooperative extension.

Gafvels, Lrthner (1993) Living with diabetes: A survey in northern Sweden Diabetes Med. 10 p. $768-773$.

Garret, H. E. (1971) Statistics in psychology and education, veils Feiffer and Simons private ltd. $6^{\text {th }}$ Indian addition Mumbai.

Keita, G. P.(2007) Psychological and cultural contributions to depression in women, considerations for women midlife and beyond, Journal of Manage Care Pham, 9, - 13.

Khan, A.P. (2004) Diabetes causes, prevention and treatment, Orient Paperbacks Publication, Delhi.

Lin, E. H., Korff, M. V., Alonson J. (2008) Mental disorder among persons with diabetes results from the world mental health survey, Journal of Psycho. Res. 65 P. 571 -580.

Lyrakos G, Papazafiropoulou A, Batistaki C, Xatziagelaki E, Damigos D, Tinas C, Spinaris V. (2013) Differences in depression anxiety and stress among men and women with diabetes mellitus.European Psychiatry 1, 28.

Roupz et. al. (2009) Anxiety and Depression in Patients with type -2 diabetes mellitus depending on sex and body mass index, Journal of Health Science, Vol. - 3, Issue -1.

Schwartz, C. (1995) Assessment of diabetes related distress, Diabetes care 18 P. 754-760

Shukla, K. C. ( 2005 ) Encyclopedic dictionary of psychology, Commonwealth Publishers, Ansari road, Darya Gang, New Delhi. 